\title{
Da memória traumática ao relato heróico: o papel da violência na identidade do Bairro da Población La Victoria, em Santiago do Chile
}

\author{
Alexis Cortés \\ Doutorando em Sociologia (Universidade Estadual do Rio de Janeiro) \\ cortes.alexis@gmail.com
}

\begin{abstract}
Resumo A partir do caso de Población La Victoria, este artigo explora a emergência da identidade de bairro gerada pela experiência de dois fatos traumáticos mediados por situações de violência: a tomada de terrenos que lhe deu origem (1957) e a resistência à ditadura militar (1973-1989). A tensão entre conflito e violência experimentados poderia ter configurado uma memória traumática e um relato vitimizante, mas criou-se um relato heróico baseado num ideário de luta, solidariedade e organização. Ele unificaria ambas as experiências numa narrativa específica, pois a ditadura veio a dar continuidade à memória dos fundadores, e a tomada forneceu um universo de significações que permitiu compreender a resistência à ditadura como uma extensão da epopeia de 1957. Para isso foi fundamental a circulação do relato mediante mecanismos como a reprodução do mito de origem, a toponímia e o muralismo.
\end{abstract}

Palavras-chave: identidade de bairro; relato heróico; memória traumática; pobladores; Población La Victoria.

\section{Introdução: violência, conflito e identidade}

$\mathrm{Q}$

UE LUGAR TEM a EXPERIÊNCIA COMPARTILHADA de situações violentas na emergência de uma identidade territorial discursivamente especificada no que se poderia chamar de identidade de bairro? Essa pergunta será a que guiará esta tentativa de exploração situada a partir do caso particular de La Población La Victoria.

La Población La Victoria, localizada no centro-sul da cidade de Santiago do Chile, é um dos assentamentos populares com maior carga histórica e simbólica da América Latina por causa da sua origem, uma tomada de terrenos, e pela resistência organizada que apresentou durante a ditadura militar do General Pinochet entre 1973 e 1989. Ambas as experiências traumáticas, que levaram a uma particular relação entre os habitantes e o território que conforma La Población, foram mediadas pela violência como ameaça potencial ou como ato real exercido sobre los pobladores. ${ }^{1}$ Entenda-se por experiência traumática um momento crítico de quebra da rotina por um evento que ameaça a integridade física de uma comunidade, assim como seu repertório de sentidos para compreender o mundo. 
Neste esforço reflexivo será fundamental a conceitualização de violência feita por Wieviorka (2006). Para o autor, na sua tentativa de elaboração de um novo paradigma sobre a violência, a compreensão desta é decorrente da distinção entre a própria violência e o conceito de conflito. Violência e conflito teriam lógicas completamente diferentes, mesmo contrastantes. Por um lado, o conflito é uma relação desigual entre duas pessoas, grupos ou conjuntos que se opõem no seio de um mesmo espaço, mas cujo alvo e horizonte não apontam para a eliminação do adversário; pelo contrário, o outro está pressuposto na constituição dos objetivos das partes, ficando descartada a ruptura entre ambas. Por outro lado, a violência física implica o fim do diálogo, a atualização da ruptura, o impedimento do debate ou do intercâmbio, mesmo que este seja desigual. Assim, o que prima é o aproveitamento da própria ruptura ou apenas a relação de força. A violência se apresenta assim como uma negação da alteridade.

Contudo, a relação entre conflito e violência é ambivalente e cheia de matizes. Como se mostrará no caso de La Población La Victoria, as experiências traumáticas da tomada de terrenos e da resistência à ditadura estão no marco da ambivalência e da tensão dessas duas categorias, sendo a tomada identificável com o conflito e a resistência, com a violência. Vale marcar que essa violência seria negativa de acordo com a perspectiva de La Población, pois os pobladores seriam objetos ou vítimas da violência exercida por parte da ditadura contra La Victoria.

A ideia de identificação da tomada com o conflito e da resistência com a violência problematiza a concepção defendida por Gabriel Salazar, pois, na sua obra La violencia política popular en las Grandes Alamedas (2006), violência e conflito se confundem no conceito de Violência Política Popular (VPP). A VPP seria um elemento estável da cultura política habitual do movimento popular chileno. Sob essa lógica, as tomadas de terrenos seriam parte de uma violência positiva exercida pelos setores populares. Concordo com Salazar sobre a concepção da tomada como uma ação direta, portadora de uma legitimidade baseada na necessidade e na noção de direito à habitação, situando-se sobre a legitimidade procedimental e formal que inspira o Estado Moderno. Sob a lógica descrita, posso compreender a tomada de terrenos de La Victoria como uma ação coletiva organizada, que significou na prática uma fratura radical com as lógicas institucionais e com a propriedade, princípio fundamental das democracias liberais. Discordo, porém, de Salazar na identificação da tomada como uma ação violenta. Desse modo, argumento que a tomada é a inauguração de uma nova esfera de conflitos na sociedade chilena.

Essa nova esfera de conflitos se faz visível, já que a tomada trouxe à tona um ator social que até esse momento não se considerava existente no espaço público: los pobladores. Esse ator coletivo estava fora também do raio de ação dos partidos políticos de esquerda que orientavam sua práxis essencialmente para o mundo operário. Com a tomada de La Victoria irrompem los pobladores como sujeitos sociais capazes de estremecer e desbordar a institucionalidade vigente, mesmo virando posteriormente um dos movimentos sociais mais importantes do Chile durante o século $\mathrm{XX}$, juntamente com o movimento operário (Garcés, 2002).

No entanto, a tomada de La Victoria não esteve isenta da ameaça real ou potencial do exercício da força física contra los pobladores. Aliás, a ação da tomada teve muito elementos de uma experiência traumática, mas que se transformou num relato heróico com marcados traços identitários. Posteriormente, a resistência à ditadura implicará a acentuação da continuidade intergeracional do relato, conformando uma identidade de bairro claramente demarcada, ou seja, uma definição de um "nós" territorialmente situado que reivindica um determinado universo valorativo e simbólico como próprio.

O presente paper será organizado em duas seções principais: primeiro, abordarei a tomada como experiência originária do relato identitário victoriano; em seguida, falarei sobre a experiência da resistência poblacional do bairro à ditadura. Finalmente, à guisa de conclusão, apresentarei uma discusão sobre os desafios deste relato identitário.

Para a elaboração deste artigo, consultei a recompilação da coleção do jornal La Voz de La Victoria (1958-1959), órgão oficial da organização dos pobladores de La Victoria durante os primeiros anos do bairro. Também utilizei os testemunhos dos protagonistas dessa história em duas etapas: primeiro, mediante os relatos de vida de los pobladores, que estiveram no início de La Población e são considerados os fundadores; segundo, mediante as entrevistas com os filhos dos fundadores, que tiveram de enfrentar diretamente a ditadura de Pinochet. Em relação ao primeiro grupo, o levantamento no campo foi realizado pelo Grupo Identidad de Memoria Popular (GIMP) no começo de 2003, agrupação da qual fiz parte. Nessa ocasião foram entrevistados 20 protagonistas ativos da tomada dos terrenos, experiência que desembocou na publicação de Memorias de La Victoria: relatos de vida en torno a los inicios de La Población (2006), inspiradas na história oral. O segundo grupo de pobladores foi entrevistado no começo do 2009, como parte do trabalho de campo de minha dissertação de mestrado, totalizando 18 entrevistas com pobladores filhos dos fundadores que ainda moravam em La Victoria.

Um dos riscos de usar a história oral é cair na ilusão biográfica (Bourdieu, 2008), ou seja, a ameaça de contribuir para a reprodução de uma ilusão retó- 
rica orientada para a apresentação em linha de uma trajetória (neste caso, coletiva), ou para a produção de um discurso oficial sobre si próprio que vise deixar uma boa impressão. Porém, precisamente um dos alvos deste artigo é apresentar o imaginário que La Población La Victoria tem de si própria, pois acredito, a partir de Boltanski (1984), que a análise do esforço social de (auto)definição e delimitação que acompanha a formação de um grupo, assim como o modo pelo qual este se autodescreve, se constitui de elementos legitimamente relevantes para compreender a constituição e objetivação de uma identidade determinada.

\section{A tomada de terrenos: a origem da identidade}

O nascimento da Victoria em 30 de outubro de 1957 tem como contexto prévio a crescente desruralização ocorrida no Chile durante a primeira metade do século XX, fomentada pelo incremento industrial e urbano, além da existência de grandes fluxos migratórios, causados pela crise do modelo primário exportador e pelo enfraquecimento da agricultura em decorrência do estímulo à indústria e às altas concentrações das terras em latifúndios (Espinoza, 1988). Esse último fenômeno provocou a absorção de população nas comunas adjacentes a Santiago, com a consequente marginalidade e o surgimento das poblaciones callampas. ${ }^{2}$

Porém, a primeira causa direta da tomada é encontrada nos assentamentos de tipo callampa instalados nas bordas do Zanjón de la Aguada. O chamado Cordón de La Miseria, na comuna de San Miguel, que, aproximadamente desde 1945, tinha cerca de 35 mil habitantes divididos em dez conjuntos. Essas famílias levaram muito tempo esperando uma solução definitiva para resolver o seu problema de habitação, pois confiavam nas promessas de Carlos Ibáñez Del Campo, então Presidente da República. No entanto, a ocorrência de dois incêndios frustrou qualquer tipo de esperança de que o governo solucionasse o problema, transformando o que era já urgente em uma necessidade imediata. Dessa maneira, ao amanhecer de 30 de outubro de 1957, cerca de 1.200 famílias organizadas numa série de comandos tomaram os terrenos da Chacra la Feria, situados na comuna de San Miguel (hoje Pedro Aguirre Cerda).

É um dado aceito que, por trás dessa ocupação ilegal de terrenos, existia um plano organizado por militantes comunistas (Millas, 1996). Fato fundamental, por um lado, pela influência dos comunistas na construção do relato e, por outro, pelo caráter organizado da tomada, num formato de plano, o que vai diferenciar La Victoria de outras meras ocupações espontâneas de terrenos (Cortés, 2008).

O caráter de "tomada", em si, representou uma forma radical de "lugarização" do espaço, ou seja, a conversão de um espaço físico alheio e indeterminado em um lugar com um valor social específico, que é apropriado tanto material como simbolicamente. Passa a se constituir como algo mais que o contexto ou pano de fundo no qual o poblador desenvolve sua vida cotidiana, formando parte essencial da construção identitária das pessoas que o habitam e o utilizam.

Entendo por "apropriação" o fenômeno que se produz quando um objeto (neste caso, o espaço) abandona o mundo das mercadorias e o sistema generalizado de equivalências e de troca (ou da mera materialidade), e passa à posse de um indivíduo ou de uma família. Assim, mediante a apropriação, os elementos se tornam autênticos e alcançam um significado particular: é o momento no qual um objeto transpassa os umbrais da relação valor uso-valor câmbio (Silverstone, Hirsch \& Morley, 1996).

\section{Poder popular e autogoverno}

A experiência de "autogoverno" dos pobladores na tomada e na consolidação da Población é fundamental para compreender o relato identitário de La Victoria. Isto é o que precisamente levou muitos pobladores a qualificar La Población como uma "pequena república", já que as condições e necessidades próprias de uma ação, que implicava uma ruptura frontal com a legalidade, significavam exigências de organização de uma magnitude e qualidade tal que levou a um desenvolvimento do que poderíamos denominar "poder popular" sem paralelos até esse momento no Chile. Apenas mediante a força que dava organização e coesão se fazia possível a permanência da tomada. Isso levou à aplicação e criação de dinâmicas e práticas extremamente originais.

É importante ressaltar que esse movimento organizativo foi uma resposta a uma situação muito adversa para os pobladores. Em primeiro lugar, eles tiveram de enfrentar a ameaça permanente de despejo por parte das autoridades, o que significou não poucos encontros violentos entre pobladores e polícia. Muitas vezes os improvisados barracões foram destruídos por carabineros (polícia chilena) e os pobladores 
tiveram de se organizar para defender a Población, sendo comumente as mulheres as que encabeçaram as tentativas de resistência.

Porém, a ameaça de expulsão não se concretizou, principalmente pela gestão do Cardeal José María Caro, que intercedeu a favor dos pobladores perante o presidente Carlos Ibáñez del Campo, o que, para Espinoza (1988), é uma prova do papel mediador dos agentes institucionais perante o Estado. Esses agentes seriam a Igreja Católica mediante El Hogar de Cristo e os partidos políticos de esquerda agrupados no FRAP (Frente de Ação Popular). Essa presença marcou um contexto de solidariedade ativado na sociedade chilena e permitiu a sobrevivência da tomada (por exemplo, a Federação de Estudantes Universitários e a Central Única de Trabalhadores).

Não obstante o despejo não ter sido realizado, os pobladores enfrentaram um bloqueio que dificultou a instalação do acampamento. Dessa maneira, o ingresso de água, remédios, materiais de construção e abrigo ficou restringido, o que dificultou a vida cotidiana dos pobladores. A adversidade das condições de moradia foi o traço típico desse período:

Armamos una pieza de madera luego de sacar los yuyos y limpiar, pero quedaban otros problemas, porque teníamos que dormir entre los bichos, en la tierra, también llegaron piojos. Y no había agua, así que teníamos luz, y como baños construíamos hoyos negros. Comenzaron a definirse los sitios y las calles, y la gente levantaba sus mediaguas, sus chozas, lo que pudieran. (Ángela Román. Memorias de La Victoria).

Nesse contexto, o fato mais traumático da tomada foram as mortes de bebês pelas condições de insalubridade que enfrentavam. Esse tópico é reiterado nos relatos dos fundadores:

En diciembre de ese año (1957) hubo una lluvia tremenda, la noche del 7 y el día 8, amaneciendo soleado el 9. Los niños se enfermaron por el cambio brusco (de temperatura), más encima muchas mediaguas no tenían techo. No sé si la cifra es exacta, puede que el corazón me engañe, pero conté 21 bebés muertos, que fuimos a enterrar a pie al cementerio, para hacer conciencia de lo que aquí pasaba. Las muertes me impactaron, sobre todo la de un niño que velaron como un angelito, cosa que nunca había visto. (Alicia Cáceres. Memorias de La Victoria).

Como já se afirmou, as condições anteriores exigiam um grande nível de organização dos pobladores. É assim como, já na tomada, se criaria o Comitê Central de Pobladores, que se coloca à frente de uma série de blocos, comitês e setores. A finalidade dos últimos era a de serem responsáveis pelo processo de urbanização - que deveriam enfrentar sem o apoio do Estado - e a de administrarem autonomamente o território tomado, sob critérios amplos de participação dos moradores.

Nas palavras de Eliecer, um dos pobladores fundadores de La Victoria:

Lo primero que se hizo fue planificar los terrenos, empezamos con urbanizar la Población haciendo todas las calles y dejando terreno para lo que necesitáramos, para la Iglesia, los carabineros, las áreas verdes y para la escuela, porque a nosotros no se nos escapó nada, queríamos una Población que reuniera todas las cualidades. (Eliecer Valenzuela. Memorias de La Victoria)

Dessa maneira, foram os moradores os próprios urbanistas de La Población: lotearam os terrenos, definiram os espaços públicos e os construíram. Para isso, organizaram planos de emulação entre os distintos blocos de La Población, premiando e estimulando aqueles pobladores que mais se destacaram pelo sacrifício nos processos de colocação de postes elétricos e na instalação do encanamento. Também se formaram comitês de vigilância, encarregados de controlar a delinquência e dar segurança a La Población. Premiaram-se os vizinhos cujo jardim era mais bonito, criou-se um jornal interno, La Voz de La Victoria, com o objetivo de que "fuera el vocero auténtico de las clases trabajadoras que viven y sufren heroicamente, sin desmayar en nuestra Población". ${ }^{3}$

O desenvolvimento organizativo era acompanhado de um discurso marcado pela rejeição assistencialista, sendo o mote mais reiterado: "Nada por caridad, todo mediante nuestro propio esfuerzo". E assim se expressava em La Voz de La Victoria: "Hemos aprendido que la lucha organizada, que la lucha revolucionaria debe ser la única manera de obligar a estas autoridades a dar preferencia a las más urgentes necesidades de la Población".

Um dos principais portadores desse capital organizativo era uma grande quantidade de quadros operários que se formaram nas lutas sindicais do norte mineiro, estando a maioria deles ligados ao Partido Comunista. Eles contribuíram significativamente para a organização da tomada e para sua posterior consolidação, sendo parte ativa da construção do relato identitário do bairro.

Entende-se, aqui, bairro como um espaço simbólico-ideológico que forma parte do imaginário urbano em três dimensões: como componente da reprodução material da sociedade e espaço físico que faz parte da cidade, como identidade social atribu- 
ída pelos atores sociais e como conjunto de valores condensados e compartilhados socialmente (Gravano, 2003). Com essa definição, o bairro, enquanto espaço de construção simbólica, supõe a disputa de significados e significações, bem como a luta permanente pela imposição de sentidos. O relato heróico de La Victoria, que alimenta a identidade desse bairro popular, também pode ser visto como o resultado de uma disputa de significados.

Durante a tomada esteve presente uma forte divisão entre um setor da Igreja Católica, encabeçado pelo sacerdote local, e outro liderado pelos militantes comunistas. Desse confronto saíram vitoriosos os últimos, e seu relato virou hegemônico. Não é objeto deste texto aprofundar essa disputa, pois o que se busca é precisamente apresentar a memória heróica como resposta aos momentos traumáticos da trajetória coletiva do bairro. Porém, é importante indicar que, por mais que o relato heróico de La Victoria se mostre como uma "memória unificada" - em contraste com o conceito de Portelli (2006) de "memória dividida", que é utilizado para dar conta da ideia de memórias em disputa -, este é o produto de um confronto de sentidos.

\section{A luta contra a ditadura}

Que condições são necessárias para que a relação com um setor social, como o dos moradores de La Victoria, transite do conflito para a violência? Uma alternativa de resposta a esse questionamento pode vir desde a perspectiva de Collins (2008). Na sua interpretação microssociológica de violência, ele situa a interação no centro da análise, procurando estudar as características das situações violentas, pois a violência não seria atributo de atores, mas sim propriedade estrutural de campos de situações. Nessa mirada, violência é uma série de passos ao redor de uma confrontação de tensão e medo, que geralmente se quebra pela presença de uma vítima fraca que se deve atacar. Por isso, a assimetria das situações resulta fundamental para superar a dinâmica tensão-medo que conduz à violência.

Precisamente isso foi o que aconteceu com o golpe militar que derrubou o governo do presidente socialista Salvador Allende, em 11 de setembro de 1973. Criou-se um contexto "especial" em que os mecanismos institucionais democráticos deixaram de ser a chave de regulação dos conflitos sociais. Com o golpe de Estado, a violência virou um mecanismo de coordenação legítimo para "refundar a nação" e para "extirpar pela raiz o câncer marxista", parafraseando a frase do General Leigh na primeira declaração da Junta Militar.

Isso inaugurou um período de sistemática violação dos direitos humanos por parte dos aparatos repressivos do Estado, ${ }^{3}$ o que implicou cárcere, torturas, fuzilamentos e desaparecimentos aplicados contra aqueles que eram considerados "inimigos internos" da nova ordem. Entre eles estava o movimiento de pobladores (Colectivo de Memoria Histórica, 2005), um dos pilares sociais do governo Allende, do qual La Población La Victoria era um dos mais conhecidos representantes.

Pela sua origem, pelo nível de organização nos anos 70, pela quantidade considerável de militantes de esquerda entre a sua população ${ }^{4}$ e pela identificação com o governo Allende, La Victoria virou um alvo privilegiado das políticas repressivas da ditadura militar. Dessa maneira, não eram somente os dirigentes ou moradores mais engajados os que viraram objeto de perseguição. A ameaça de violência atingia a coletividade como um todo, o que se sintetizava na intimidante possibilidade de bombardeio de La Población por parte da Força Aérea, segundo o depoimento dos moradores:

[El 11 de septiembre lo vivimos] con miedo, con mucho miedo, porque supuestamente iban a bombardear la Población. Iban a bombardear La Legua y La Victoria, después bombardearon la Iglesia. Y el miedo era grande, ver tanto milico [militar], sí poh, si el miedo era grande. Pienso yo que no sería capaz de vivir otro golpe de estado. (Sara Torres, 55 años)

Embora a ameaça de bombardeio não se concretizasse, durante os primeiros dias da ditadura um acontecimento exerceu simbolicamente a função de cristalizar a advertência militar contra a coletividade de La Victoria: o bombardeio da Igreja local. Esse fato adicionou à situação de incerteza na qual se encontravam os moradores a declaração por parte das novas autoridades de que se iniciava uma guerra contra eles:

La Población fue muy golpeada con el golpe [sic], por ejemplo cuando el Padre Santiago que en ese entonces estaba a cargo de la parroquia, dice que toda la gente se refugie en la parroquia y jmenos mal que la gente no fue a la parroquia!, porque fue la primera

3. Assim consta nos informes da Comisión Nacional de Verdad y Reconciliación (1991) e da Comisión Nacional sobre Prisión Política y Tortura (2004).

4. Segundo estimações de Bentué (1972) para o ano 1971, em La Victoria o Partido Comunista tinha aproximadamente 470 membros entre militantes e simpatizantes oficiais, enquanto o Partido Socialista cerca de 220. 
en ser bombardeada, siendo que se supone que todo lo que tiene que ver con religión es sagrado y no se puede tocar y ellos sí lo tocaron. (Cathya Arancibia, 46 años)

Durante esse período se produz um refluxo organizacional, por um lado, pela perplexidade provocada pela passagem de uma situação político-social em que os moradores de La Victoria eram os protagonistas privilegiados de um projeto de futuro para um contexto em que agora eles viravam objeto de perseguição e repressão. Por outro lado, a organização social precisou ficar em barbecho, em suspensão, pois muitos dirigentes e militantes tiveram de se ocultar e passar à clandestinidade para evitar engrossar as listas de executados políticos.

Porém, paulatinamente, em La Victoria se produzirá uma substituição geracional das lideranças, e os jovens ocuparão o espaço deixado pelos dirigentes perseguidos. A primeira tarefa que eles enfrentaram, segundo a sua própria definição, foi "vencer o medo", para tentar recompor o tecido organizacional:

La tarea era concientizar a la Población, que hay que tomar una bandera de lucha y decidirse y no tener más miedo, porque el miedo en esos años era terrible. Tú cuando participabas en algo muchos vecinos no te hablaban por lo mismo, por el miedo que sentían de que alguien los involucrara a ellos en esto; entonces esa fue como primera tarea dar la cara y que no había que tener miedo. Esa fue como la primera tarea de todos. (Iván Lemuñir, 50 años)

Esses esforços levaram a que nos anos 80 se desenvolvessem, em La Victoria, inéditas formas orgânicas que coincidiram, em âmbito geral, com o começo de uma oposição sistemática ao regime. Nesse contexto, La Población La Victoria tem um papel de protagonista na resistência e oposição à ditadura.

Um dos momentos que exigiu mais organização por parte dos moradores foi coordenar os protestos nacionais contra a ditadura. Isto os levou a constituir o Comando de Pobladores, uma nova organização na qual todos os partidos de esquerda estavam representados, e que teve a missão de substituir a antiga Junta de Vecinos proibida pela ditadura. Assim, uma ex-líder descreve a formação e algumas das principais tarefas:

Después de la primera protesta nos damos cuenta de que debíamos tener primeros auxilios, se generan los primeros equipos al calor de la misma protesta, se empiezan a generar los equipos de bomberos, que eran los encargados de apagar las bombas lacrimógenas, los equipos que se hacían las zanjas por cuadras, que eso permitía que si bien no parara la policía, la pensaban dos veces, por últimos retrasaban el ingreso a la Población. Y de ir teniendo postas que iban avisando por dónde iba la policía, por dónde entraban los milicos, hicimos un equipo de mujeres en esos años que participaban principalmente con el cura André Jarlan y el Pierre Dubois, que salíamos cada vez que había una protesta a dar una vuelta por la Población para hacer un chequeo y para tener las menores bajas posibles en lo que significaba una jornada a otra de represión, porque de repente, llamábamos a una jornada de un día, pero que para nosotros significaba tres, cuatro días, por los allanamientos masivos que se nos hacían o los allanamientos selectivos que habían después de cada protesta o después de cada asesinato que tuvo la dictadura. (Soledad Araos, 48 años)

A violência exercida pela ditadura gerava organização em La Victoria, a resposta das autoridades era mais repressão, o que, segundo os moradores, era contestado novamente com mais organização. $\mathrm{O}$ convencimento era que só a unidade, a organização e a solidariedade permitiriam preservar a sua integridade física e recuperar a democracia.

É importante distinguir que o exercício da violência física pela ditadura se realizou em duas dimensões: por um lado, existia uma violência seletiva, cujo alvo eram dirigentes políticos, sindicais, universitários e poblacionales; por outro, havia uma violência massiva, contra toda a população (toque de queda) que se acentuava nos setores populares como las poblaciones. Em La Victoria, ambas as violências se aplicaram. Prova disso são os dois detenidos desaparecidos: dois executados políticos e sete assassinados durante os protestos nacionais, entre os quais está o sacerdote francês André Jarlan.

Porém, do ponto de vista da conformação de uma identidade coletiva, a violência seletiva não pareceu produzir um efeito tão estruturante quanto a violência massiva. As vítimas da violência seletiva se incorporaram no relato como mártires, mas a forma particular com que se produziram as desaparições ou detenções não permitia uma apropriação maior por parte do coletivo do acontecimento como uma tragédia experimentada compartilhadamente. Por exemplo, no caso dos detenidos desaparecidos, eram pessoas que saíam um dia de suas casas, eram sequestradas e nunca mais voltavam. Diferente era quando a violência seletiva se aplicava aos dirigentes ativos de La Población, quando os moradores ativavam dispositivos de emergência para evitar a detenção, transformando o evento em um acontecimento coletivo (apedrejamentos).

A violência massiva implicou uma situação repressiva que era compartilhada por todos. Por exemplo, no caso dos allanamientos (invasões de domicílio) por parte de carabineros ou das forças armadas, ou no 
caso da repressão durante os protestos. A condição de moradores de La Victoria os convertia indistintamente em objetos potenciais da repressão:

Ahí comenzó la represión ya masiva (años '80), el primer allanamiento masivo que se hizo a los pobladores de La Victoria, donde se nos llevó a una cancha de futbol allá en Departamental, vejando a medio mundo y de ahí pa delante hasta el 87 más o menos que duró la represión masiva... yo me acuerdo que una vez venía yo llegando del sur de una actividad que estaba realizando yo en el sur, llego como a las cinco de la mañana y al ratito empezamos a escuchar los micrófonos que decían que era un allanamiento masivo, que teníamos que salir todos pa'fuera, ahí nos tuvieron en el estadio San Eugenio. Todos los varones menores de 65 años y mayores de 15 ó 18 años, no me acuerdo, estoy hablando del mes de octubre del 85, si no me equivoco. (Félix Morales, 52 años)

O caráter assimétrico da situação em que se encontravam os moradores diante dos aparatos repressivos do Estado levavam a situações de extrema violência física. Os moradores eram alvo de vexames e humilhações múltiplas, em que a noção de alteridade ficava anulada:

Era atroz ver el ensañamiento que tenían con los chiquillos sobre todo. Los hacían caminar sobre las fogatas, con los pies quemados. Una vez recibimos un niño que no sé con qué le pegaron, pero en todas las articulaciones: en los codos, en las rodillas. Según ellos era para mantener el orden, pero no, era ensañamiento lo que había. El disparo, de frente para que les llegaran perdigones y no sé poh, sacar cientos de perdigones, era todo de aquí [cuello] hasta abajo... Después el año 84 cuando mataron al cura ahí fue tremendo, tremendo. Me tocó estar ahí. Y después incluso estando no sé quién de mandamás de la Iglesia Católica, el monseñor no sé cuantito; se meten los militares y a los chiquillos los tomaban del pelo y les cortaban así el pelo, le sacaban con piel y todo... les tomaban el pelo y era como sacar una peluca con toda la piel, les dejaron como los huesos, aquí [cabeza], descubiertos. Era atroz, que tú no piensas que un ser humano pueda hacer eso, de poder hacerle eso a otro ser humano. Con bayoneta cortarles los glúteos, era como dejarlos... [silencio] ¡Tal ensañamiento! Y ese día fue atroz. (Marta Robles, 53 años)

Aliás, a resistência "victoriana" - melhor dito, o desigual enfrentamento contra a ditadura - começou a ser reconhecida como um bastião da luta contra a ditadura, e seus moradores se tornaram sinônimos de rebeldia e organização. A grande quantidade de perdas humanas contribuíram para construir esse imaginário durante esse período. Cada morte de um poblador era interpretada como um "sacrifício vicário" que se fazia em nome de "todos", não um crime individual ou particular, mas um crime contra a coletividade, contra La Población. Assim, cada funeral de um "mártir" se tornava um ato de protesto contra a ditadura, La Población se esvaziava de moradores para marchar para o cemitério, o que era contestado pela ditadura com mais repressão.

"La Victoria era diferente" é o que se escuta reiteradamente nos depoimentos dos moradores. Como La Población era atacada como um todo, a resposta organizada - ou espontânea - também se fazia como um todo. Sempre um morador encontrava uma porta aberta para se proteger da perseguição da polícia, "não como em outros lados". O nível de "apropriação" do espaço dos victorianos se mostrava na disposição de evitar que as forças repressivas entrassem no bairro: "que les costara entrar a la Población, porque era nuestra, nosotros la habíamos tomado" (Blanca Ibarra, 60 años).

Contudo, entre todas as experiências repressivas vividas na Población, a que causou maior impacto simbólico foi a morte do sacerdote francês André Jarlan em 4 de setembro de $1983,{ }^{5}$ no curso de um protesto nacional. Ele morreu lendo a Bíblia no seu quarto por causa de uma bala perdida de carabineros, cujo alvo era um grupo de jornalistas que tentava se ocultar na capela dos sacerdotes. A bala se desviou e foi parar na cabeça do padre, que morreu instantaneamente.

A notícia da morte de André Jarlan expandiuse pela Población e indignou os moradores, que já tinham lamentado a morte de um jovem durante o dia. Espontaneamente os moradores colocaram velas no meio de cada rua como manifestação de repúdio ao ato realizado pela polícia. Com isso transformaram a Población em um grande velório coletivo.

A morte de André Jarlan foi impactante para La Victoria por duas razões. Primeiro, pela sua condição de sacerdote, o que, segundo a concepção dos moradores, lhe outorgava uma condição de "intocável" perante a ditadura. Ele era um "homem de Igreja", um "homem sagrado" que devia ser respeitado pela ditadura. Sua morte evidenciava que ninguém estava protegido, deixando ainda mais na indefensabilidade La Victoria e seus moradores. Segundo, o fato de ter sido morto sem participar dos protestos e por uma "bala perdida" mostrava que essa bala poderia ter atingido qualquer outro morador, razão pela qual foi interpretada como uma bala que todos 
receberam. Uma antiga liderança descreve assim o acontecimento:

Todos los asesinatos fueron terribles, todas las pérdidas, pero lo más lo más demostrativo, porque los demás, los cabros murieron en la calle, mirando o en una fogata que pasó un auto y disparó; pero aquí lo más terrible fue que André estaba leyendo la Biblia en su dormitorio, en el segundo piso de la capilla. Entonces ahí tomamos conciencia del tema de las balas locas, a él le tocó pero podría haber sido un niño, podría haber sido una mujer que ni siquiera estaba en la protesta. Yo creo que la conmoción que produjo el asesinato de André fue que éramos personas que estábamos absolutamente indefensas de las balas locas... Lo peor fue que la Dictadura para justificar el asesinato trata de inventar que había sido asesinado por el otro sacerdote, que había caído en protesta. Y mientras él murió a nosotros nos habían asesinado un joven a las 10, 11 de la mañana, a Andrés Barrales en 30 de octubre, mirando. Y en la tarde a André. Fueron dos muertos que tuvimos ese 4 de septiembre de $1984 \ldots$ Mientras nosotros informábamos la muerte de André a la Población seguían los allanamientos, la represión no paraba. Y lo otro la actitud de los jóvenes que querían ir a enfrentarse a la dictadura a pecho descubierto, fueron momentos muy duros, muy terrible para nosotros tratar de neutralizar y hacerles tomar conciencia con mucha rabia, con mucha pena a los jóvenes que lo único que querían era ir a enfrentarse con carabineros, con la represión o con lo que fuera. (Claudina Núñez, 55 años)

André Jarlan se tornou um ícone da resistência poblacional contra a ditadura - o mártir principal de um relato de heroísmo do qual a coletividade foi protagonista. Notável é que na construção deste discurso, a experiência da tomada é considerada como antecedente de uma mesma história. O relato identitário considera a tomada e a experiência da ditadura como uma trajetória contínua, como as duas faces de uma mesma moeda. A resistência contra a ditadura é interpretada pelos moradores como a continuação da epopeia de origem, como uma herança dos ensinamentos dos fundadores: "La Victoria é luta, organização e solidariedade". Dessa maneira, reconhecia-se que La Victoria era diferente, embora outras comunidades se destacassem também pela sua oposição ao regime. $\mathrm{O}$ que explicava sua tenacidade na resistência era sua história, era a origem de tomada.

Ahora los jóvenes han seguido nuestro mismo camino. Ellos están luchando por sus derechos. Para mí fue muy emocionante un mural que se pintó en la Población que decía: "nuestros padres nos dieron el derecho a la vivienda, démosle nosotros el derecho a la libertad”. (Morales, [1987?], p.7)
El orgullo de ser victoriano viene indudablemente de la formación que tuvimos, con los viejos que se tomaron esta cuestión, fue organización desde antes y después de la toma, porque se mantuvo en el tiempo, yo creo que ese es como un legado, como una herencia que quedó de la capacidad de organización. (Félix Morales, 52 años)

A experiência traumática da ditadura, em especial pelas perdas humanas, veio alimentar uma memória heróica, na qual - como os entrevistados reconhecem - La Victoria ficou no imaginário urbano como um exemplo de capacidade de resistência, valentia e organização.

Durante a ditadura ativaram-se mecanismos de circulação do relato identitário que ainda hoje persistem em La Victoria e teriam a função de prover continuidade ao relato entre as novas gerações, sendo suporte da memória coletiva da Población. São eles: a reatualização do mito de origem, a toponímia e o muralismo.

A reatualização do mito de origem, mediante a celebração do aniversário e da reconstituição da tomada, permite dar "frescor" à experiência distante da tomada, permitindo a conexão entre passado e presente. Essa atividade reiterativa do passado não se interrompeu na ditadura; pelo contrário, se exacerbou, sendo considerada como uma mostra do afinco por afirmar a história própria contra as tentativas ditatoriais que procuravam eliminar a identidade do sujeito poblador.

Na toponímia - ou seja, na particular maneira de nomear o espaço (ruas) - existe uma tentativa de ligar a biografia da Población com a história do movimento social chileno e mundial. Ruas como Carlos Marx, Unidad Popular (coalizão do governo Allende) ou as que lembram matanças de operários ou camponeses são exemplo disso. Durante a ditadura, o regime tentou mudar os nomes e substituí-los pelos de militares, mas os moradores negaram-se, pois, para eles, mudar os nomes seria macular sua identidade. Assim, eles continuaram nomeando as ruas do jeito antigo e repondo cartazes com os nomes antigos sobre os nomes oficiais.

Também durante a ditadura desenvolveu-se o muralismo como uma forma de ter um suporte físico de mensagens políticas breves, destinadas a manter viva a chama da resistência depois do Golpe de Estado. Posteriormente o muralismo complexificou-se iconograficamente, mobilizando o imaginário do período Allende, conjugando expressão artística com denúncia política, como uma forma de desabafo, de ruptura do silêncio ao qual estavam condenados pela ditadura. O mural foi um dos poucos meios para denunciar as mortes dos moradores e a situação de precariedade econômica em que se encontravam. A ditadura fez múltiplas tentativas de acabar com essa 
expressão, pichando sistematicamente os muros de La Victoria, mas os moradores pintavam novamente. Eles não negociavam sua soberania sobre o espaço público de La Población, reafirmando um universo de valores associado ao "ser victoriano": rebeldia, valentia e organização.

$\mathrm{Na}$ atualidade, a expressão "muralista" persiste com o propósito de expor graficamente a memória heróica da Población, enfatizando a recuperação do mito de origem e a experiência da ditadura, fundindo ambas as experiências em uma única história.

A experiência proporcionada pela ditadura implicou um trabalho de significação política dos pobladores para levar ao mundo do dizível as diversas violações a que foram submetidos. Ao mesmo tempo, mobilizou-se a própria experiência da tomada como fonte de sentidos para compreender a nova situação, transformando o que poderia ser uma memória traumática em uma memória heróica. Porém, nem por isso neste relato deixaram de existir silêncios sobre a experiência da ditadura, assim como mágoas entre familiares de vítimas de violência seletiva pelo abandono e menor visibilidade delas se comparadas às vítimas da violência massiva. Aliás, um elemento que está ausente nos depoimentos e nos registros bibliográficos sobre o período em La Victoria é a situação dos pobladores que foram vítimas da repressão ditatorial não por razões políticas, mas sim por terem antecedentes penais. ${ }^{6}$ É possível que esse silêncio se relacione com a necessidade de os victorianos afirmarem sua identidade contra um imaginário da cidade que associa La Victoria a um lugar de luta, mas também de delinquência e droga.

\section{Considerações finais}

O relato identitário do bairro de La Población La Victoria alimentou-se de duas experiências compartilhadas, fundamentais na biografia coletiva e individual dos seus moradores: a tomada de terrenos e a resistência à ditadura militar. Ambas fizeram que o espaço em que moravam não fosse apenas um pano de fundo da vida cotidiana, mas sim o suporte físico da afirmação de um projeto coletivo e o fator de conexão entre as trajetórias particulares e a trajetória da comunidade.

Temporalmente, e também de modo geracional, a experiência da ditadura deu continuidade à memória dos fundadores, pois a experiência da tomada forneceu um universo de significações que permitiu dar sentido à resistência e compreender a nova situa- ção como uma extensão de uma epopeia iniciada em 1957 quando os terrenos foram ocupados.

As experiências traumáticas, que são a fonte principal da identidade victoriana, transitaram pela tensão entre conflito e violência, na qual a ameaça física e a precariedade de condições de vida poderiam ter configurado uma memória traumática e um relato vitimizante. Mas, segundo Wieviorka (2006, p. 108),

un mouvement social ou cultural qui s'enferme dans une représentation 'victimiste' de lui-même, des acteurs de l'histoire qui, selon le mot de l'historien Salo Baron, réduisent leur expérience historique à un récit 'lacrymal' tendent à tourner en rond, à ne rien construire et à ne pouvoir se projeter que vers le passé.

No entanto, em La Victoria criou-se um relato para além da sua condição de vítimas, não se definindo pela perda de algo ou pela ausência, mas sim pela afirmação de um relato heróico que reivindica um determinado universo de valores como próprio: La Victoria seria luta, solidariedade e organização. É a decisão dos fundadores de conquistar um lugar onde viver o que ajuda a explicar a capacidade de mobilização dos moradores durante a ditadura, porque "fueron nuestros padres los que nos enseñaron". Isso é o que permite ao relato identitário victoriano se projetar no futuro e não ficar apenas no passado.

$\mathrm{Na}$ atualidade, os níveis de organização e participação não chegam aos alcançados durante a ditadura, mas los victorianos se reconhecem ainda como "la Población más organizada de Chile" e como os portadores de um capital organizativo latente que pode se atualizar em qualquer momento. Isso é exemplificado pelos moradores nos casos de mudança do sistema de coleta de lixo e de mudança do plano regulador da comunidade, os quais implicaram mobilizações massivas. A lógica é que, assim como foram capazes de ocupar os terrenos, ou de lutar contra a ditadura, serão capazes de enfrentar outras vicissitudes.

A presença da droga chegou a ser o principal problema de La Victoria, pois o narcotráfico chegou a disputar o espaço público com as organizações sociais, mas na atualidade o problema está em grande parte controlado pelo fortalecimento da organização social e pela presença de políticas governamentais que conjugaram intervenção social e ação policial. Isto não significa que o problema tenha desaparecido. Na verdade, o problema do narcotráfico continua sendo o principal desafio para a persistência do relato identitário, fenômeno que espero abordar em outros trabalhos.

Este texto se baseou nos relatos de duas gerações de victorianos, faltando ainda conhecer o grau de iden- 
tificação que as novas gerações (terceira, quarta) têm com o relato victoriano - um tema para outro esforço interpretativo. Porém, muitos desses jovens são os que atualmente formam parte dos clubes esportivos locais, das novas brigadas muralistas, das rádios populares, do canal local Señal 3 de La Victoria. Por isso, não é apressado afirmar que a produção simbólica, associada ao relato identitário, transcendeu seu tem- po. As experiências da tomada e da resistência à ditadura estão enraizadas nos pobladores atuais em uma magnitude tal que seguramente os fundadores nunca suspeitaram quando, na madrugada de 30 de outubro de 1957, com poucas roupas, bandeiras e muitas esperanças, tomaram para si um lugar de Santiago e o chamaram de Población La Victoria.

\section{Referências}

BENTUÉ, Antonio. Religión y marginalidad social en la Población La Victoria de Santiago (Chile): reflexión teológica. Strasbourg, 1972. Tese (Doutorado em Teologia) - Facultad de Teología, Universidad de Strasbourg, 1972 .

BOLTANSKI, Luc. How a social group objectified itself: 'cadre' in France, 1936-1945. Social Science Information, v. 23, n. 3, p. 469-491, 1984.

BOURDIEU, Pierre. A ilusão biográfica. In: MORAES FERREIRA, Marieta; AMADO, Janaína (Orgs). Usos e abusos da história oral. Rio de Janeiro: Ed. Fundação Getulio Vargas, 2006. COLECTIVO DE MEMORIA HISTÓRICA. Tortura en poblaciones del Gran Santiago (1973-1990). Santiago: Coroporación José Domingo Cañas, 2005.

COLLINS, Randall. Violence: a micro-sociological theory. Princeton: Princeton University Press, 2008.

CORTÉS, Alexis. Los comunistas y la toma de terrenos de La Victoria: a 50 años de una de las tomas más grandes de Latinoamérica. Alternativa (ICAL), n. 25, p. 92-101, 2008.

ESPINOZA, Vicente. Para una historia de los pobres de la Ciudad. Santiago: Ediciones Sur, 1988.

GARCÉS, Mario. Tomando su sitio. Santiago: Ediciones Lom, 2002.

GRAVANO, Ariel. Antropología de lo Barrial: estudios sobre la producción simbólica de la vida urbana. Buenos Aires: Espacio, 2003.
GRUPO IDENTIDAD DE MEMORIA POPULAR. Memorias de La Victoria. Santiago: Quimantú, 2006.

MILLAS, Orlando. Memorias: 1957-1991. Santiago: Cesoc, 1996. MORALES, Carlos. La Victoria de Chile. Santiago: La Llama, [1987?].

PORTELLI, Alessandro. O massacre de Civitella Val di Chiana (Toscana: 29 de junho de 1944): mito, política, luto e senso comum. In: MORAES FERREIRA, Marieta; AMADO, Janaína (Orgs.). Usos e abusos da história oral. Rio de Janeiro: Ed. Fundação Getulio Vargas, 2006.

SALAZAR, Gabriel. La violencia política popular en las "Grandes Alamedas": la violencia en Chile 1947-1987 (Una perspectiva histórico popular). Santiago: Ediciones Lom, 2006.

SILVERSTONE, Roger; HIRSCH, Eric; MORLEY, David. Tecnologías de la información y de la comunicación y la economía moral de la familia. In: SILVERSTONE, Roger; HIRS$\mathrm{CH}$, Eric (Orgs.). Los efectos de la nueva comunicación. Barcelona: Bosch, 1996.

VERDUGO, Patricia. André de La Victoria. Santiago: Aconcagua, 1985.

WIEWIORKA, Michael. La violence. Paris: Hachette Littérature, 2006. 


\title{
From the traumatic memory to the heroic account: the role of violence in the neighborhood identity of La Población La Victoria in Santiago de
}

\section{Chile}

\begin{abstract}
From the case of La Población La Victoria, this paper explores the emergency of neighborhood identity created by the experience of two traumatic facts mediated by situations of violence: the take-over of the land (1957) and the resistance to the dictatorship (19731989). The tension experimented between conflict and violence could have configured a traumatic memory and a victimized account. But a heroic narration based on the notion of struggle, solidarity and organization was created. This unified both experiences in a specific narrative, because the dictatorship gave continuity to the founders' memory and the take-over of the land provided a body of significations that permitted to understand the resistance to the dictatorship as an extension of the epic of 1957. The circulation of the account through the reproduction of the foundation's myth, the toponymy and the muralism had a fundamental role in this process.
\end{abstract}

Key-words: neighborhood identity; heroic account; traumatic memory; pobladores; Población La Victoria.

\section{De la memoria traumática al relato heroico: el papel de la violencia en la identidad barrial de la Población La Victoria en Santiago de Chile}

\section{Resumen}

A partir del caso de la Población La Victoria, este artículo explora la emergencia de la identidad barrial generada por la experiencia de dos hechos traumáticos mediados por situaciones de violencia: la toma de terrenos que le dio origen (1957) y la resistencia a la Dictadura Militar (1973-1989). La tensión entre conflicto y violencia experimentados podría haber configurado una memoria traumática y un relato victimizante. Sin embargo, se creó un relato heroico basado en un ideario de lucha, solidaridad y organización. Éste unificaría ambas experiencias en una narrativa específica, pues la dictadura dio continuidad a la memoria de los fundadores y la toma proporcionó un universo de significaciones que permitió comprender la resistencia a la dictadura como una extensión de la epopeya de 1957. Para ello, fue fundamental la circulación del relato por medio de los mecanismos de reproducción del mito de origen, de la toponimia y del muralismo.

Palabras clave: identidad barrial; relato heroico; memoria traumática; pobladores; Población La Victoria.

Data de recebimento do artigo: 10/03/2011

Data de aprovação do artigo: 29/07/2011 